sucinuti-4nthutharis cartamints-with the following results :In seven instances I cut the loop (and sometimes a second one) which the caterpillar had spun; and in all the chrysalis was excluded without falling down; but, in no case was the tail of the chrysalis withdrawn from the pocket of the old caterpillarskin, so that its suspension is directly from the latter. In eleven cases in which I did not interere, only two chrysalids were excluded in the normal way, i.e., vertically, with the head up, a girdle round the insect and the chrysalis-tail withdrawn from the old skin and attached immediately to the silk on the stem of the plant. In three other cases in which a loop was spun by the caterpillar, the chrysalis seems to have turned upside-down during exclusion, the tail being now uppermost, the loop tavisted, and the hooks fastened in loose silk upon the plant-stem. Six caterpillars either spun no loop at all or one so insufficient that they became suspensi of themselves before exclusion began, and were all but one (which fell down) successfully excluded in this position-the tail of the chrysalis, however, being still retained within the pocket of the old skin.

The most interesting and curious point in the transformation of a caterpillar of the suspentsi is the manner in which the newlyexcluded chrysalis is kept from falling, while its hook-furnished tail is being withdrawn from the old skin of the caterpillar and made fast in the cone of silk to which the latter was attached. I am ignorant whether any other explanation of this prucess has been given than that, I believe, originally communicated by Réaumur and detailed in Kirby and Spence, vol. iii. pp. 208209 , and repeated in such recent works as Figuier's "Insect World," from the English edition of which work by Prof. P. Martin Duncan (1872), p. I48, I quote the following account of the pupation of Vanessa urtice: :- "But here 'comes the culminating point, the most difficult part of the operation. The chrysalis, which is shorter than the caterpillar, is at some distance from the silky network to which it must fix itself it is only supported by that extremity of the caterpillar's skin which had not been split open. It has neither legs nor arms, and yet it must free itself from this remaining part of the skin, and reach the tbreads to whech it is to suspend itself. The suffle and contractite syments of the chrysalis serve for the limbs tohich are voantints to it. Between two of these segments, as nivill a pair of pincers, the insect seize's a portion of the folded slin, and wi the such a firm hald that it is able to suffort the wohole of its livily on it. It now curves the hinder parts slightly, and draws its tail entirely out of the sheath in which it was inclosed," \&c. (The italics are mine.) How this can be conceived possible, considering the utterly soft condition of the newly-excluded pupa, and that the caterpiliar skin is now "reduced to a packet so small that, it covers only the end of the tail of the chrysalis" (loc. cit.), in which, moreover, there are no longer any free segments, I cannot understand. On the ither hand, it is very casy to show that the last and sufficient bond of connection between the chrysalis and the old larva-skin is a membrane extending from the lining of the latter to the anterior horns of the two lateral ridges bounding the analarea of thechrysalis. I have prepared several specimens showirg this membrane still intuct, and should be happy to forward one or two, if required, fur inspection. I find it in all three species of butterfly mentioned above, and I believe it is to the persistence of it unbruken that is owing the continued suspension of my chrysalides of Anthocharis. I have tested its strength to sustain the weight of the chrysalis, and the time during which it resists desiccation and the writhings of the insect, the obvious object of which is, not to get rid of the old caterpillar-skin, but to rupture this membrane after the chrysalis has made good its tail-attachment to the silk.

Milford, Letterkenny

\section{The Satellites of Mars}

Ir is not necessary to have an enormous telescope in order to see the outer satellite of Mars. I had a very satisfactory view of it on September 15 at 9 h. $20 \mathrm{~m}$. with a nine-inch reflector, and only lost it in the planet's glare at about Ioh. 50m. I would have written to you on the subject earlier, but was not aware that it was considered so extremely difficult an object until I read the letters in your paper of the 27 th ult.

The Lizard, Cornwall, October 6

\section{Rate of Mound-Building}

This papers announce that Mir. Layard has obtained permis. sion to renew excavations in the Mesopotamian Valley. Several other explorations will be in progress during the coming season in countries where no trained labour can be obtained. I write to beg the gentlemen having the work in charge to make some accurate observations as to the amount of dirt which a man can move in a day with rude implements, noting the distance as well. A discussion has sorung up concerning the time required to build our Mississippi Valiey mounds, The investigation of which I speak will thro s some light on the subject.

Washington, D.C., September 26 OTIS T. MAsON

\section{OUR ASTRONOMICAL' COLUMN}

THE Melbourne OBSERvatory. - The twelfth Rerort of the Board of Visitors of this Observatory, addressed to the Governor of Victoria, with the Annual Report of the Government Astronomer, is before us. It presents an outline of the work accomplished between June 20,1876 , and May 22, 1877 , and of the work in progress and in prospective. With the great reflector, which is in charge of Mr. Turner, the observation and drawing of Sir John Herschel's figured nebulæ has been continued. A finished drawing of the Horse-shoe Nebula, M. 17, has been made, together with drawings of fifty-seven of the smaller nebula. The publication of this work is in progress; out of ninety-three drawings which it is intended to publish, sixty-one are already lithographed; they are representations of the nebulae on a black ground, and Mr. Ellery states that they render the telescopic appearance of the objects in a most effective and truthful style, and if the lithographic printers succeed in obtaining the requisite number of copies as ferfect as the proof copies which were subnitted to the Board of Visitors, he considers that "the whole difficulty of economically and satisfactorily reproducing these astronomical drawings will be surmounted." The descriptive letter-press will be ready by the time the lithography is finished, and it is expected that before the next annual inspection of the Observatory this first instalment of results furnished by the great telescope will have been distributed over the colonies and throughout Europe and America. With the "South equatorial" Mr. Ellery has been engaged upon a work of no small interest and astronomical value, viz, the re-measurement of the double-stars contained in Sir John Herschel's Cape Catalogue, $1834-38$, in which revision he is promised the co-operation of Mr. Todd with the Adelaide refractor. Mr. Ellery further mentions that be hoped to utilise the present opposition of Mars, in connection with northern observatories, for a determination of the solar parallax. The transit-circle observations, which are regarded as the main work of the establishment, are zealously continued. The magnetic and meteorological work is upon the same general plan as hitherto, but the former was likely, at the date of the Report, to suffer some interruption from the necessity of erecting a new magnetic-house.

The OUter Satellite of Mars. - Though this object will no doubt be growing fainter with the increasing distance of the planet from the earth, a few positions are subjoined which have been deduced from elements fairly representing measures made by $\mathrm{Mr}$. Common, at Ealing, to the end of September. The two or three days when the moon will be near to Mars are omitted :-

At 8\%, 3om. Grentwich Mean Time.

Oct. 11 ... Pus. 69 ... Dist. 66 Oct. 20 .. Pus. 42 ... Dist. 37

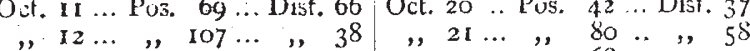

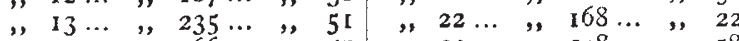

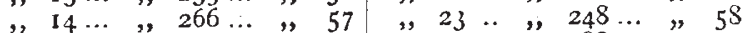

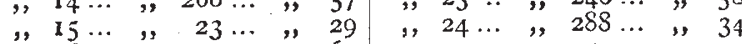

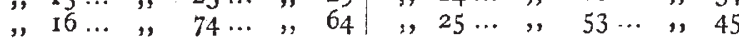

At the times mentioned in Lord Rosse's letter (NATURE, vol. xvi. p. 457) the calculated places of the satellite were as follows :- September 8 , at $11 \mathrm{~h} .45 \mathrm{~m}$., pos. $70^{\circ}$, dist. $8 ;^{\prime \prime}$, and Septeriber 15, at 1 h. 3orn., pos. $246^{\circ}$, dist. $79^{\prime \prime}$.

The period of revolution given by measures between 